\title{
A Method of Separating Sponge Spicules by Filtration.
}

By

\author{
L. R. Crawshay, M.A.
}

THE separation of sponge spicules by the method here described has been employed by me from time to time, for some years past, with such satisfactory results that it may be recommended with confidence as a useful and time-saving method of preparing these or other minute hard structures for microscopic examination.

For the suggestion of gun cotton as a filtering medium I am indebted to Mr. D. J. Matthews, the simple apparatus adopted for its use being as follows :-

A piece of glass tubing, about half an inch in inside diameter and eight inches in length, is drawn out at one end rather abruptly to an opening of about one-eighth of an inch or less, and this tube is passed through a cork which serves to support it while resting loosely in the neck of a flask or other waste receptacle. A very small piece of gun cotton, first teased out evenly, is then pressed lightly with a glass rod into the lower drawn-out end of the tube. This plug should be of the smallest possible bulk sufficient to ensure easy filtration, and need not be more than about one-eighth of an inch in depth.

The spicules having first been cleaned in a test tube by boiling in nitric acid or Eau de Javelle, and the test tube having been filled up with distilled water in the ordinary manner, the contents are poured into the tube and, the liquid passing through the filter, the tube is refilled with distilled water and afterwards twice with $90 \%$ alcohol. The filter carrying the spicules is then pressed backwards into the tube and shaken out through the broad end into a small test tube in which the filter is thoroughly dissolved by shaking it up in equal parts of pure ether and absolute alcohol, the tube being fitted with a cork to prevent evaporation of the ether. When the spicules have settled the liquid is pipetted off and the test tube is refilled with ether and alcohol and shaken up as before. After pipetting off for the second time the tube is then filled with $90 \%$ alcohol, from which after being allowed to settle again, the spicules may be removed for mounting on the slide. In this way the gun cotton is removed in solution. If it is not, a deposit will be left on the slide when the liquid is burnt off which will more often spoil 
the preparation, and there is a danger too of the spicules being partly fused by the high burning temperature of the gun cotton.

The method has the advantage of much saving of time over that of allowing the spicules to settle naturally in a test tube through the process of cleaning and dehydration, and ensures a degree of completeness which is greater perhaps than either this or the centrifuge method. When a very small fragment only of a sponge is available, or where spicules are of very small size or scarce in the specimen, it is especially serviceable as retaining the whole of the spicules within a narrow compass, thus obviating loss of material. Filtration may be accelerated by means of a pressure pump if necessary, though it is better as far as possible to avoid this owing to any additional pressure tending to pack the spicules too closely on the filter or to break them. If through the filter being too lightly adjusted too rapid filtration should occur, any spicules that may have passed through can of course be recovered by refiltering the waste liquid, and in view of this it is best to observe always the same precaution in regard to cleanness for the flask as for any tubes or pipettes that are used. Any of the latter that have been used in contact with the dissolved gun cotton should be washed in the first instance in ether and alcohol to ensure thorough cleaning and the removal of spicules clinging to traces of the residue.

Though the method has been employed almost solely for the separation of sponge spicules, there seems no reason why it should not be found of equal service in the treatment of Diatom tests, the shields of Coccolithophoridæ, or any other minute structures which are uninjured by ether or alcohol. 